\title{
Investigation of sewage sludge gasification with use of flue gas as a gasifying agent
}

\author{
Izabella Maj $^{1{ }^{1 *}}$, Edyta Kudlek $^{2}$, Piotr Ostrowski ${ }^{1}$ and Marek Pronobis ${ }^{1}$ \\ ${ }^{1}$ Silesian University of Technology, Institute of Power Engineering and Turbomachinery, \\ Konarskiego 20, 44-100 Gliwice, Poland \\ ${ }^{2}$ Silesian University of Technology, Institute of Water and Wastewater Engineering, Konarskiego 18, \\ 44-100 Gliwice, Poland
}

\begin{abstract}
The paper presents results of investigation of low-temperature sewage sludge gasification with use of flue gas as a gasifying agent. Tests were conducted in a laboratory stand, equipped with a gasification reactor designed and constructed specifically for this purpose. During presented tests, gas mixture with a composition of typical flue gases was used as a gasifying agent. The measuring system ensures online measurements of syngas composition: $\mathrm{CO}, \mathrm{CO}_{2}, \mathrm{H}_{2}, \mathrm{CH}_{4}$. As a result of gasification process a syngas with combustible components has been obtained. The aim of the research was to determine the usability of sewage sludge for indirect cofiring in power boilers with the use of flue gas from the boiler as a gasifying agent and recirculating the syngas to the boiler's combustion chamber. Results of presented investigation will be used as a knowledge base for industrial-scale sewage sludge gasification process. Furthermore, toxicity of solid products of the process has been determined by the use of Microtox bioassay. Before tests, solid post-gasification residues have been ground to two particle size fractions and extracted into Milli-Q water. The response of test organisms (bioluminescent Aliivibrio fischeri bacteria) in reference to a control sample (bacteria exposed to $2 \% \mathrm{NaCl}$ solution) was measured after 5 and 15 minutes of exposure. The obtained toxicity results proved that thermal treatment of sewage sludge by their gasification reduces their toxicity relative to water organisms.
\end{abstract}

\section{Introduction}

Gasification is a process of thermochemical conversion of a carbon-based feedstock into a combustible product gas with the use of a gasifying agent, such as steam, air or gas mixtures. Depending on the source, the gasification temperature is defined above $700-950^{\circ}$ $\mathrm{C}$, with a combustible gas as a main product of the process, what differs gasification from pyrolysis. The technology discussed in this paper is defined as a low-temperature gasification, due a temperature range lower than in typical gasification process and a combustible gas as a main product. In general, oxygen, air or steam are used as gasifying agents [1], while in discussed investigation synthetic flue gase with composition of $\mathrm{N}_{2}, \mathrm{CO}_{2}$

\footnotetext{
* Corresponding author: izabella.maj@polsl.pl
} 
and $\mathrm{O}_{2}$ are used. To the best of our knowledge there is very limited data regarding alternative fuels gasification with flue gases as a gasifying agent. However, increasing number of studies under coal and biomass thermal conversion are paying attention to use $\mathrm{CO}_{2}$ and air- $\mathrm{CO}_{2}$ mixtures as a gasifying agent. There are some experimental studies on pyrolysis of coal and biomass under $\mathrm{N}_{2}$ and $\mathrm{CO}_{2}$ atmosphere separately [2], however no mixture of this gases have been used.

The amount of sewage sludge has been increasing due to escalation of World's population and higher standard of living in developing countries. The disposal of waste such as sewage sludge in a pressing problem. It is necessary to implement effective and environmentally safe disposal way immediately, hence growing numbers of sewage sludge thermal utilization studies have been performed last years. Thermal processes involve converting of the organic part of the sewage sludge, resulting with final disposal of ashes only. Sewage sludge is a type of biomass fuel with a calorific value ranging up to value of a coal. In recent decades ono- and co-combustion of sewage sludge are probably the most developed thermal utilization methods, however technologies of gasification and pyrolysis are developing constantly [3, 4].

Results of presented investigation will be used as a knowledge base for industrial-scale sewage sludge gasification process. Industrial-size rotary gasification reactor using the flue gas as a gasifying agent has been designed and successfully built in a power plant in Radlin town. In field of sewage sludge gasification and pyrolysis some studies of rotary kiln and fixed bed reactors are known $[5,6]$ but mainly in a laboratory scale. However no studies were found in the literature about the gasification of sewage sludge with use of flue gases as gasifying agent. The main aim of presented laboratory study is to investigate an usability of sewage sludge to gasification process in an industrial-size rotary reactor prior to cofiring the process' product (syngas) in power boilers.

\section{Laboratory research}

Laboratory research was conducted to develop design requirements and to identify the usability of sewage sludge for low-temperature gasification in industrial-scale reactor. Tests were performed in relation to the planned construction of the industrial installation and conducted in a laboratory stand, equipped with a gasification reactor designed and constructed specifically for this purpose (Fig. 1)

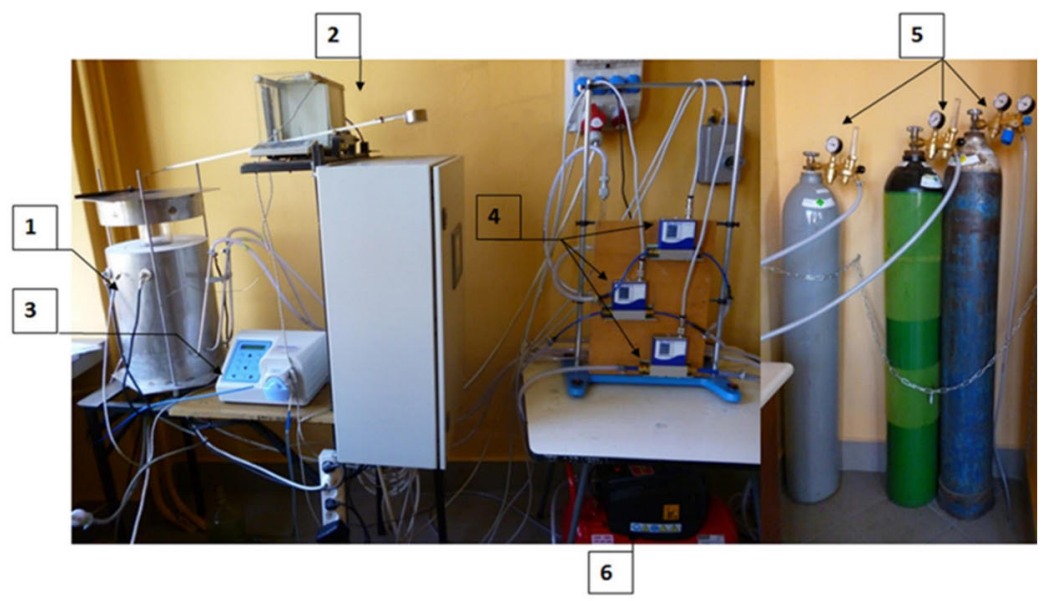

Fig. 1. Experimental gasification stand (1-reactor, 2-scales, 3-water pump, 4-gas flow meters, 5-gas tanks, 6-air compressor). 
The experimental stand enables the weight loss of a sample and resulting gas composition to be recorded. The sample mass is approximately $3 \mathrm{~g}$, which distinguishes the method from the classic TGA method, which is frequently used for fuel thermal conversion investigations. Moreover, in classic thermogravimetric analysis the process temperature rises with a set heating rate, while the discussed experimental setup enables to place the fuel sample in a constant temperature field and to keep the temperature stable throughout the measurement. This type of thermogravimetric analyzer may be used to determine thermal behavior of wide range of fuels during their combustion or other thermal treatment. Presented experimental setup enables to investigate gasification, pyrolysis, torrefaction and combustion, depending on agent composition and temperature requested. The station provides a possibility for the thermal degradation of an alternative fuel sample of approx. 3 $\mathrm{g}$ in the temperature range of $180-750^{\circ} \mathrm{C}$ with a gasification agent of a known composition and humidity.

The measuring system ensures online measurements and recording trends of:

- temperature

- $\quad$ mass loss

- composition of process gas

Before laboratory tests, properties of sewage sludge has been determined and presented in table 1 .

Table 1. properties of the dried sewage sludge.

\begin{tabular}{|l|l|l|}
\hline Parameter & Value & Unit \\
\hline Lower heating value & 10214 & $\mathrm{~kJ} / \mathrm{kg}$ \\
\hline Ash & 27,5 & $\%$ \\
\hline Moisture & 7,2 & $\%$ \\
\hline
\end{tabular}

\section{Low-temperature gasification results}

During presented tests of low-temperature sewage sludge gasification gas mixture with a composition of typical flue gas was used as a gasifying agent. On-line measurement of syngas composition revealed significant shares of combustible components $\left(\mathrm{CO}, \mathrm{H}_{2}, \mathrm{CH}_{4}\right)$. At the same time the weight loss of a fuel sample have been recorded (Fig. 2)

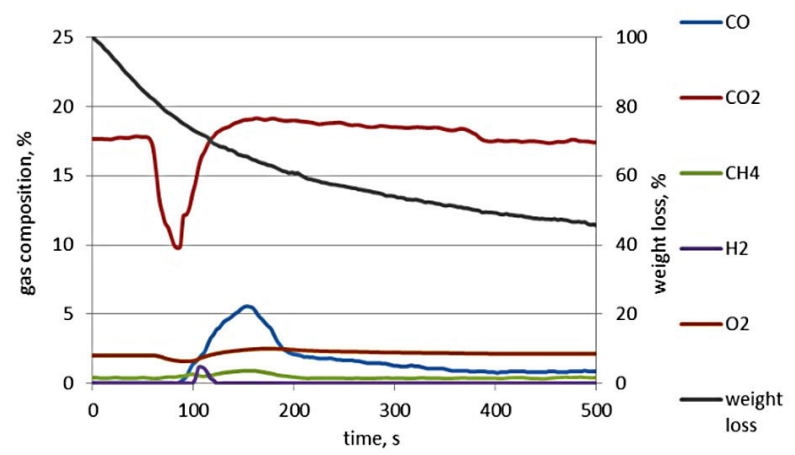

Fig. 2. Weight loss and gas composition for $550^{\circ} \mathrm{C}$ sewage sludge gasification. 
Tests conducted in the temperature range of $350-550^{\circ} \mathrm{C}$ with the application of synthetic flue gas as a converting agent identified the impact of the process temperature on the concentration of the selected combustible components $\left(\mathrm{CO}, \mathrm{CH}_{4}\right.$ and $\left.\mathrm{H}_{2}\right)$ in the process gas (Table 2).

Table 2. Time constant and maximum combustible components concentration

\begin{tabular}{|c|c|c|c|c|c|}
\hline Temperature & $\mathrm{T}$ & $4 \mathrm{~T}$ & $\max \mathrm{CO}$ & $\max \mathrm{CH}_{4}$ & $\operatorname{max~}_{2}$ \\
\hline${ }^{\circ} \mathrm{C}$ & $\mathrm{s}$ & $\mathrm{s}$ & $\%$ & $\%$ & $\%$ \\
\hline 350 & 598 & 2392 & 2,06 & 0,80 & 0,40 \\
\hline 450 & 564 & 2256 & 3,55 & 1,38 & 0,40 \\
\hline 550 & 495 & 1980 & 6,07 & 1,01 & 1,14 \\
\hline
\end{tabular}

Note: $\mathrm{T}$ - time constant, in field of process dynamics, defined as a time of reaching $63 \%$ of conversion. $4 \mathrm{~T}$ defined as a time of full conversion (in inertial model process).

Depending on the process temperature, the reduction time was determined for $63 \%$ of the organic part of the fuel (Table 2). On this basis, the recommended time for the fuel to remain in the reactor was established, which was fourfold higher than the process time constant $\mathrm{T}$ (reduction time of $63 \%$ of organic part of the fuel).

\section{Toxicity}

The toxicity measurements of water samples after a $15 \mathrm{~min}$ and $24 \mathrm{~h}$ contact time with sewage sludge before and after gasification were carried out according to the Screening Test procedure of MicrotoxOmni system in Microtox analyzer Model 500. The Microtox ${ }^{\circledR}$ bioassay registers the change in the intensity of light emitted by test organisms, which are the bioluminescence bacteria Allivibrio fisheri exposed to toxic substances.

The rate of bioluminescence inhibition in reference to a control sample ( $2 \% \mathrm{NaCl}$ solution) was measured after 5 and 15 minutes of exposure.

Absorbance measurement was performed by the use of a UV/VIS CECIL spectrophotometer model CE 1021 by Cecil Instruments Limited

The toxicological evaluation was made to assess the impact of sewage sludge before and after its gasification process on the environment. This allows for comprehensive evaluation of the feasibility of sewage sludge gasification taking into account its storage both as a substrate prior gasification and as a waste product. Figure 4 presented the change in the toxicity of water exposed to sewage sludge before and after gasification in 350, 450 and 550 ${ }^{\circ} \mathrm{C}$. Dry sewage sludge of a granulation of $\leq 0.5$ after a 15 min contact with water increases its toxicity according to toxicity classes [7] to the level of low toxic solutions. For the $24 \mathrm{~h}$ exposure the toxicological effect assume values exceeding $50 \%$, which indicates the elution of substances form sewage sludge which have a negative impact on the test organisms and inhibit their metabolic processes. The water was classified as toxic. Water extracts of sewage sludge of a granulation greater than $0.5 \mathrm{~mm}$ do not exhibit a adverse effects on test organisms. Only bacteria after a 15 min contact time with solution after a $24 \mathrm{~h}$ extraction indicated a low toxicity of the tested samples. 
a)

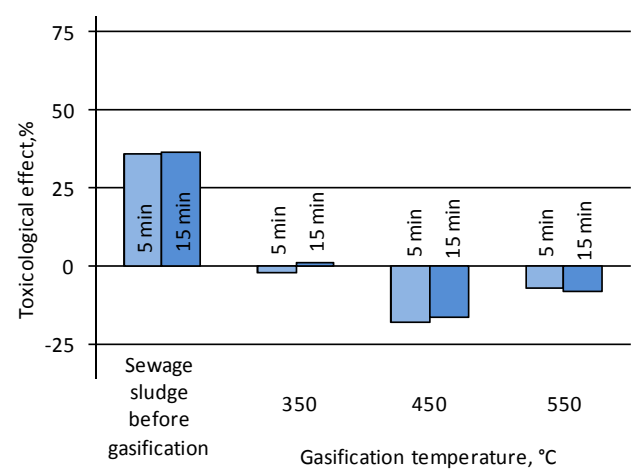

b)

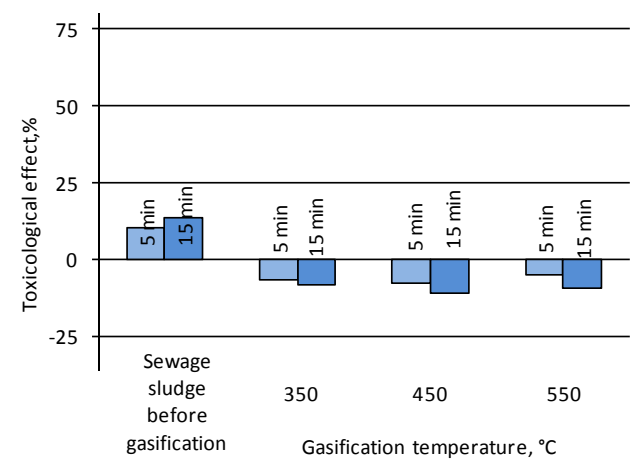

$24 \mathrm{~h}$ extraction with water
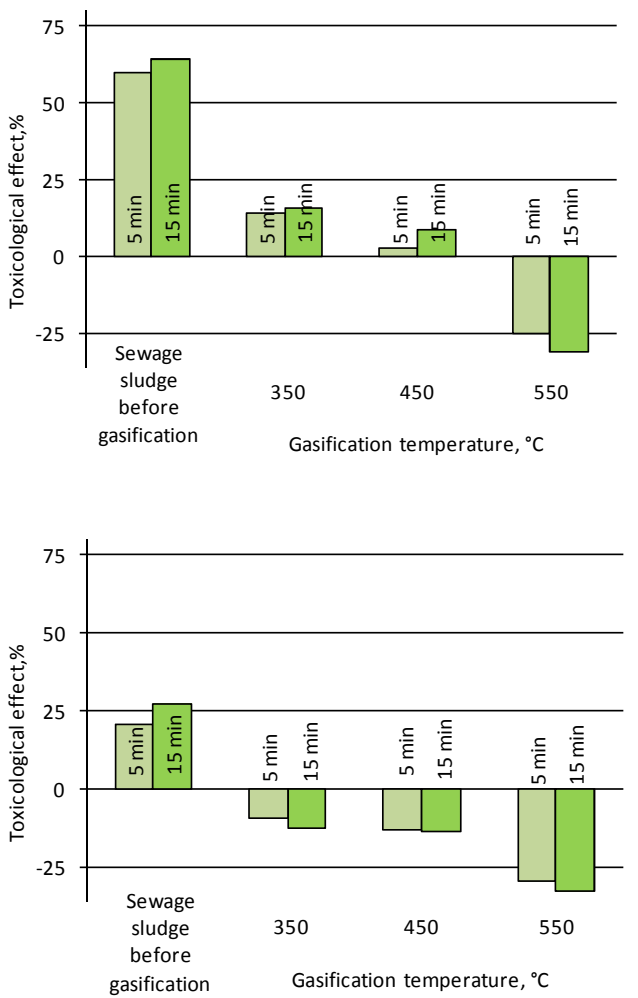

Fig. 3. Changes of toxicity of water after $15 \mathrm{~min}$ and $24 \mathrm{~h}$ extraction of sewage sludge and sewage sludge ashes with the granulation of a) $\leq 0.5 \mathrm{~mm}$ and b) $>0.5 \mathrm{~mm}$

Water extracts of post-gasification sewage sludge ashes pointed a positive impact on living organisms. The toxic effect takes negative values. This phenomena indicated a stimulation of metabolic processes of bacteria relative to control sample. The gasification process results in the removal of the organic compounds from sewage sludge and decrease their negative properties. It should be emphasized that the organic compounds next to heavy metals are responsible for the negative impact on different ecosystems including the aquatic environment. The decrease of organic compounds has been proven by absorbance measurements at wavelength of $254 \mathrm{~nm}$ corresponding to the absorbance maximum for organic compounds (Fig 4.). 


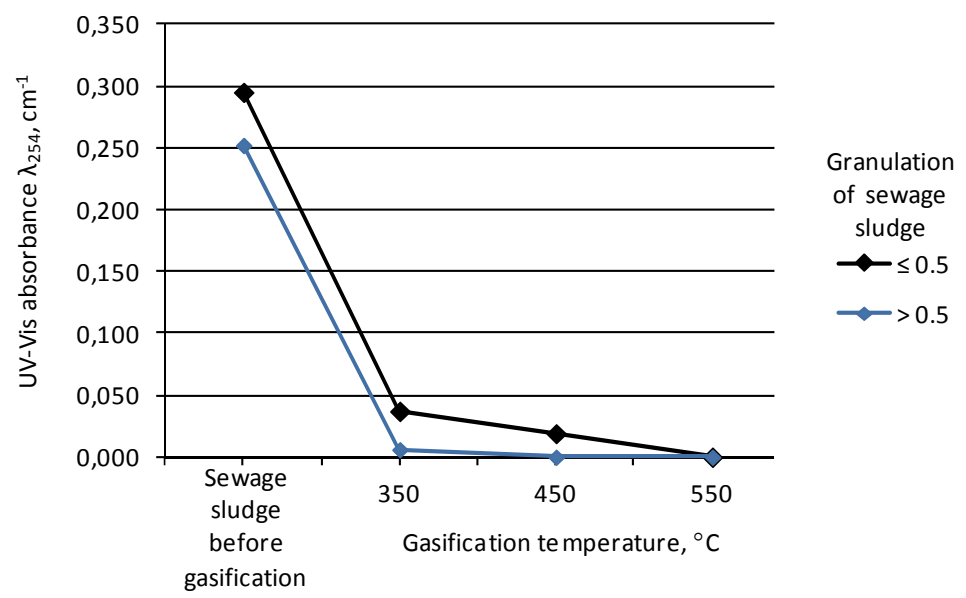

Fig. 4. Decrease of the concentration of organic substances in the gasification process expressed by the UV-Vis absorbance measurement

\section{Industrial-size installation}

Presented laboratory tests aimed to identify the usefulness of sewage sludge and to establish design recommendations to industrial-scale gasification process. The large-scale process can be performed in rotary gasification reactor using boiler flue gas as the converting medium (Fig 5).

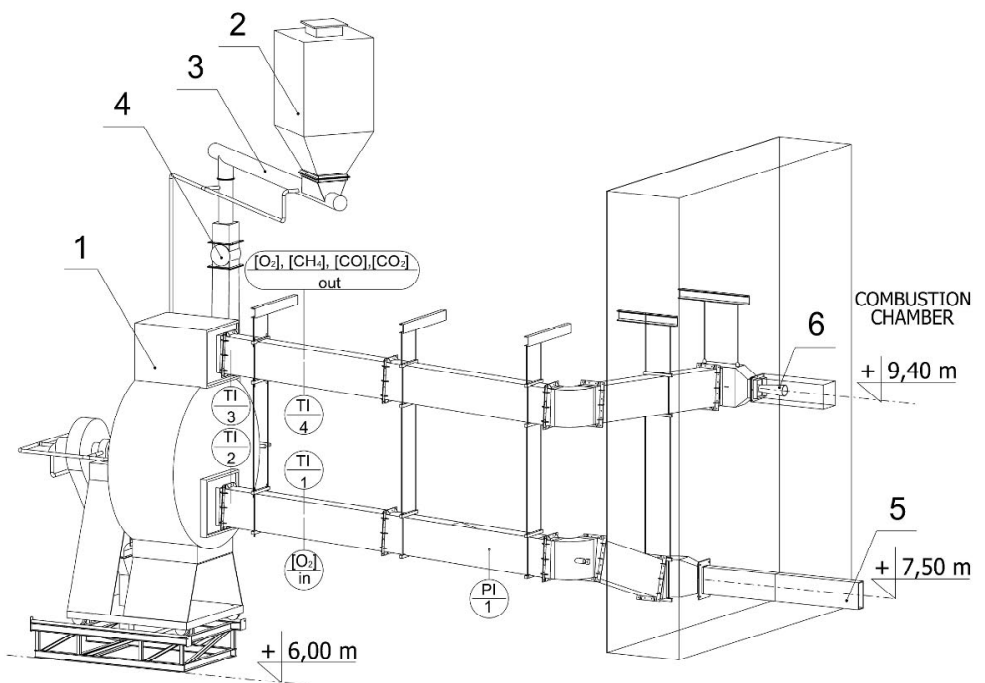

Fig. 5. Industrial-size installation concept (1-rotary reactor, 2-fuel container, 3-screw feeder, 4-rotary feeder, 5-suction duct, 6-injector) 
The reactor is connected to the boiler, which implies recirculation of the product gas (syngas) into the combustion chamber. The solid products of the gasification process are transported to the container equipped with a water lock. A helical line of working vanes inside the reactor ensure continuous transport of solid products towards the chute. The construction of the reactor enables to use a wide range of alternative fuels (biomass, industrial and municipal waste). Industrial-size rotary gasification reactor using the flue gas as a gasifying agent has been designed and successfully built in Marcel power Plant in Radlin town, south of Poland. An obvious advantage of this technology is its considerable flexibility relative to the properties of the co-fired fuel (water content, particle size, composition), which is particularly important due to seasonality and the non-homogeneity of alternative fuels. Furthermore, this technology achieves high thermal shares of co-firing and separation (of solid products and ashes) from the thermal degradation installation and from the boiler, which enables their separate utilisation, e.g., as a fertiliser. The technology of using boiler flue gas as the converting medium has been developed at the Institute of Power Engineering and Turbomachinery of the Silesian University of Technology for several years.

\section{Conclusions and further operation}

During presented tests of low-temperature sewage sludge gasification gas mixture with a composition of typical flue gas was used as a gasifying agent. On-line measurement of syngas composition $\left(\mathrm{CO}, \mathrm{CO}_{2}, \mathrm{H}_{2}, \mathrm{CH}_{4}\right)$ revealed significant shares of combustible components. At the same time a weight loss of a fuel sample have been investigated to determine the kinetics of a process and recommended time for the fuel to remain in the reactor. Results of presented investigation will be used as a knowledge base for industrialscale sewage sludge gasification process. Industrial-size rotary gasification reactor using the flue gas as a gasifying agent has been designed and successfully built in a power plant in Radlin town, south of Poland. Several successful tests of the installation have been performed witch use of biomass feedstock (wood pellets). Low-temperature sewage sludge gasification in this industrial-size reactor will be the next step after presented laboratory research.

Moreover the toxicological tests have been performed to determine the impact of solid gasification products (sewage sludge ashes) on water organisms. The toxicological test results of water after a $15 \mathrm{~min}$ and $25 \mathrm{~h}$ contact time with sewage sludge ashes does not indicate a toxic effect on living organisms. Whereas dry sewage sludge before gasification process has a negative impact on the investigated sample. Presented tests demonstrated the impact of sewage sludge thermal treatment on their toxicity and show that even the lowest investigated process temperature $\left(350^{\circ} \mathrm{C}\right)$ greatly reduces the toxicity of the process products, hence their further disposal would be less restricted due to the environmental issue.

This paper is the result of investigations conducted with the funds BKM/554/RIE5/2014. 


\section{References}

1. J. Speight, Gasification of Unconventional Feedstocks, Chapter 3 - Gasifier Types, 54 (2014)

2. S. Zellagui, C. Schönnenbeck, N. Zouaoui-Mahzoul, G. Leyssens, O. Authier, E. Thunin, L. Porcheron, J.-F. Brilhac, Fuel Processing Technology, Pyrolysis of coal and woody biomass under $\mathrm{N} 2$ and CO2 atmospheres using a drop tube furnace experimental study and kinetic modeling, 148, 99 (2016)

3. D. Fytili, A. Zabaniotou, Renew Sust Energ Rev, Utilization of sewage sludge in EU application of old and new methods - a review, 12, 116 (2008)

4. S. Werle, Ecol Chem Eng S., Sewage sludge-to-energy management in Eastern Europe: a Polish perspective, 22, 459 (2015)

5. Y. Chun, S.Kim, K. Yoshikawa, Applied Energy, Pyrolysis gasification of dried sewage sludge in a combined screw and rotary kiln gasifier, 88, 1105 (2011)

6. S. Werle, Energy Procedia, Gasification of a Dried Sewage Sludge in a Laboratory Scale Fixed Bed Reactor, 66, 253 (2015)

7. S. Werle, M. Dudziak, Chemical Review, Evaluation of tixicity of sawage sludge and gasification waste-products, 92 (2013) 